INFLAMMATORY BOWEL DISEASE

\title{
Infliximab in inflammatory bowel disease: clinical outcome in a population based cohort from Stockholm County
}

\author{
T Liung, P Karlén, D Schmidt, P M Hellström, A Lapidus, I Janczewska, U Sjöqvist, R Löfberg
}

Gut 2004;53:849-853. doi: 10.1136/gut.2003.018515

See end of article for authors' affiliations

Correspondence to:

Dr T Liung, Department of Gastroenterology and Hepatology, Karolinska Institute at Karolinska Hospital, SE-171 76 Stockholm, Sweden; tryggve.ljung@ks.se

Accepted for publication 25 November 2003
Background: Several placebo controlled studies have demonstrated the efficacy of infliximab in inflammatory bowel disease (IBD) but the potential toxicity of this new biological compound has been less studied.

Aim: To assess the use of infliximab in IBD in a population based cohort, with special emphasis on the occurrence of severe adverse events and mortality.

Patients: All patients with IBD treated with infliximab between 1999 and 2001 in Stockholm County were evaluated.

Methods: Prospective registration of clinical data was carried out. Retrospective analyses were made of possible adverse events occurring in relation to infliximab treatment. Adverse events requiring pharmacological treatment or hospitalisation were defined as severe. Clinical response was assessed as remission, response, or failure.

Results: A cohort comprising 217 patients was assembled: 191 patients had Crohn's disease (CD), and infliximab was used off label for ulcerative colitis (UC) in 22 patients. Four patients were treated for indeterminate colitis (IC). Mean age was 37.6 (0.9) years (range 8-79). The mean number of infliximab infusions was $2.6(0.1)$ (range 1-11). Forty two severe adverse events were registered in 41 patients (CD, $n=35)$. Eleven of the severe adverse events occurred postoperatively $(C D, n=6)$. Three patients with $C D$ developed lymphoma (of which two were fatal), opportunistic infections occurred in two patients (one with $U C$, fatal), and two patients with severe attacks of IBD died due to sepsis (one with CD, one postoperatively with UC). One additional patient with UC died from pulmonary embolism after colectomy. Mean age in the group with fatal outcome was 62.7 years (range $25-79$ ). The overall response rate was $75 \%$ and did not differ between the patient groups.

Conclusions: Infliximab was efficacious as an anti-inflammatory treatment when assessed in a population based cohort of patients with IBD. However, there appear to be a significant risk of deleterious and fatal adverse events, particularly in elderly patients with severe attacks of IBD. Off label use of infliximab in UC and IC should be avoided until efficacy is proven in randomised controlled trials. The underlying risk of developing malignancies among patients with severe or chronically active $C D$ in need of infliximab treatment is not known but the finding of a $1.5 \%$ annual incidence of lymphoma emphasises the need for vigilant surveillance with respect to this malignant complication.
I nfliximab is a chimeric IgG4 monoclonal antibody targeting tumour necrosis factor $\alpha$ (TNF- $\alpha$ ). Randomised clinical trials have proven the efficacy of infliximab in moderately to severely active luminal Crohn's disease (CD), and in CD with draining fistulas. ${ }^{12}$ Moreover, maintenance treatment with infliximab has shown that this regimen is reasonably safe and that steroid withdrawal can be achieved in the majority of patients. ${ }^{3}{ }^{4}$ However, one problem with studies evaluating the effects of infliximab in CD is the lack of a true placebo group as most patients have been exposed to the compound at least once. ${ }^{34}$ This makes comparisons and risk estimates of adverse events and occurrence of malignancies difficult or even impossible. Pooled data from all Centocor sponsored clinical trials, involving 2292 patients, showed comparable death rates among placebo and infliximab treated patients $(2 \%$ and $1 \%$, respectively) and similar occurrence of serious infections. ${ }^{5}$ However, case reports describing fatal opportunistic infections after infliximab treatment have been presented. ${ }^{67}$

Furthermore, as TNF- $\alpha$ has been shown to be important in wound healing, ${ }^{8} 9$ there may be a potential risk that major surgery after infliximab treatment could lead to complications in the postoperative course.

Another important issue is concern over the development of malignancy associated with the use of infliximab, especially lymphoma. ${ }^{10}$ At the time of approval in the USA, four cases of lymphoma had occurred among patients treated with infliximab in various clinical trials.

The Food and Drug Administration in the USA concluded that a causality between infliximab and the development of lymphoma was considered unlikely but pointed out that the limited number of patients treated made it impossible to exclude a relationship. ${ }^{11}$ Infliximab has now been used in more than 150000 patients with CD, and several further cases with lymphoma and malignancies in general have been reported during post-marketing surveillance (report (PSUR 7) submitted to European Health Authorities on 4 April 2003). The current background risk for developing lymphoma or malignancies in moderately to severely affected CD patients is not known but recent reports from population based studies have indicated that lymphoma among patients aged 20-40 years is a rare event and that the baseline risk of lymphoma in patients with CD is not significantly increased compared with the general population. ${ }^{12-15}$ Moreover, the risk of concomitant use of immunomodulatory treatment with

Abbreviations: TNF- $\alpha$, tumour necrosis factor $\alpha$; CD, Crohn's disease; UC, ulcerative colitis; IBD, inflammatory bowel disease; IC, indeterminate colitis; GCS, glucocorticosteroids; 6-MP, 6-mercaptopurine; 5-ASA, 5-aminosalicylic acid 
azathioprine or 6-mercaptopurine (6-MP) does not seem to confer an increased risk of malignancy. ${ }^{16}{ }^{17}$

The main aim of the present study was to evaluate the outcome of infliximab treatment for IBD conditions in a population based setting in Stockholm County, Sweden. Special emphasis was directed towards treatment of patients with severely active IBD and towards the outcome of major surgery in those patients where infliximab treatment failed. In addition, postoperative complications were monitored. The overall incidence of severe adverse events and mortality were also assessed.

Simple analysis of efficacy was carried out in order to compare the results in the study cohort with those obtained in previous clinical trials.

\section{MATERIALS AND METHODS} Study population and design

To accurately assess the efficacy of infliximab and adverse events in clinical use, we evaluated all patients with IBD, including $\mathrm{CD}$, ulcerative colitis (UC), and indeterminate colitis (IC) patients, treated with infliximab in Stockholm County between January 1999 and April 2001.

Eleven medical centres contributed to the study, including two academic paediatric gastroenterology units, accounting for all centres providing infliximab treatment for IBD in this area with a registered total population of 1831046 inhabitants (as of 31 December 2001). From the launch of infliximab in Sweden, consecutive patients with IBD in Stockholm County were prospectively included into the study database at the time of their first infusion. The following data were recorded: age, sex, diagnosis and anatomical distribution of IBD, concomitant medical treatment, indication for infliximab, number of infusions, clinical response, severe adverse events, surgical intervention, as well as 30 day postoperative outcome.

Infliximab (Remicade; Centocor, Malvern, Pennsylvania, USA) was administered at a dose of $5 \mathrm{mg} / \mathrm{kg}$ body weight as a two hour intravenous infusion. The total number of infusions given to each patient was dependent on the indication.

Patients received infliximab during their hospital stay in cases of severely active IBD or as outpatients if activity was moderate. All patients were monitored for adverse advents during and at least one hour after infusion. Clinical response and late adverse events were evaluated at the follow up clinical visit. To assess the clinical response, a simple three step category scale according to Cohen and colleagues ${ }^{18}$ was used: for patients with luminal disease, failure implied no change or worsening of symptoms; response implied improvement or tapering of glucocorticosteroids (GCS) without worsening; and remission implied absence or near absence of all clinical symptoms without an increase in GCS dose. For patients with fistulising disease, failure implied no change or worsening of symptoms, response implied improvement of at least one fistula, and remission implied closing of all fistulas.
Clinical outcome was assessed one month after the first infliximab infusion in cases of luminal disease, and one month after the third infliximab infusion in cases of fistulising disease.

A severe adverse event was defined as clinical symptoms that required active pharmacological treatment and/or hospitalisation, and thus did not include minor and more common infusion reactions such as pruritus, rash, headache, "flu"-like symptoms, or chest-pain, if those conditions did not require medication or observation.

The incidence of lymphoma and malignancy was compared with the overall incidence of malignancy in the Stockholm County background population 1999-2001, based on data from the National Cancer registry which records all cancers in Sweden.

The protocol was approved by the regional ethics committee at the Karolinska Institute in Stockholm.

\section{Statistical methods}

Quantitative variables are described as mean (SEM). Groups were compared using the Kruskal-Wallis test followed by Dunn's post test. A p value $<0.05$ was considered statistically significant.

\section{RESULTS}

\section{Baseline characteristics of the study population}

A total of 217 patients ( 105 women and 112 men; mean age $37.6(0.9)$ years (range 8-77)) received a mean of $2.6(0.1)$ infliximab infusions (range $1-11)$ ). The majority of patients had CD $(n=191), 22$ had UC, and the remaining four had IC.

Among patients with $\mathrm{CD}$, involvement was limited to the small bowel in $13(7 \%)$, it was ileocolonic in 67 (35\%), and colorectal in the remaining $111(58 \%)$ patients. In CD patients, the indication for infliximab infusion was active luminal disease in 148 (77\%) cases and perianal fistulas in 43 (23\%). In nine patients with UC, the reason for infliximab infusion was longstanding GCS refractory left sided disease, and in the remaining UC patients the indication was acute GCS refractory extensive colitis $(n=12)$ or active inflammation in the remaining rectum after ileorectal anastomosis $(\mathrm{n}=1)$. Four patients had longstanding GCS dependent IC.

A total of $111(51 \%)$ were receiving concomitant therapy with azathioprine or 6-MP, 117 (54\%) had GCS treatment, and 54 patients $(25 \%)$ were receiving both azathioprine/6-MP and GCS treatment. Eighty patients $(37 \%)$ were on long term 5 -aminosalicylic acid treatment. Forty three patients $(20 \%)$ received therapy with oral metronidazole.

\section{Severe adverse events and mortality}

In 41 patients, a total number of 42 severe adverse events were observed (table 1) during the study period. Eleven of those events were related to surgery.

Six fatal adverse reactions were encountered (table 2). Death was caused by lymphoma in two cases (both with CD),

Table 1 Severe adverse events

\begin{tabular}{lccll}
\hline Severe adverse event & No & Fatal & CD:UC & Specific comments \\
\hline Lymphoma & 3 & 2 & $3: 0$ & $\begin{array}{c}\text { One NK cell lymphoma } \\
\text { and two B cell lymphomas }\end{array}$ \\
Infection & 11 & 2 & $7: 4$ & \\
Postoperative infection & 7 & 1 & $4: 1$ & \\
Thromboembolic event & 5 & 1 & $4: 1$ & \\
Delayed hypersensitivity reaction & 5 & 0 & $5: 0$ & \\
Anaphylactic reaction & 3 & 0 & $3: 0$ & \\
Urticaria & 5 & 0 & $5: 0$ & \\
Miscellaneous (systemic lupus erythematosus, & 3 & 0 & $3: 0$ & \\
$\quad$ depression, vestibular neuritis) & & & & \\
\hline CD, Crohn's disease; UC, ulcerative colitis; NK, natural killer. & & &
\end{tabular}


Table 2 Fatal adverse events

\begin{tabular}{|c|c|c|c|c|c|c|c|}
\hline Diagnosis & $\begin{array}{l}\text { Age } \\
\text { (y) }\end{array}$ & Sex & $\begin{array}{l}\text { Concomitant } \\
\text { medication }\end{array}$ & $\begin{array}{l}\text { No of } \\
\text { infusions }\end{array}$ & $\begin{array}{l}\text { Time between first infusion } \\
\text { and adverse event }\end{array}$ & Cause of Death & Specific comments \\
\hline$C D$ & 25 & $M$ & Azathioprine+GCS & 1 & $1 y$ & NK cell lymphoma & $\begin{array}{l}\text { Tissue staining positive for } \\
\text { TNF- } \alpha\end{array}$ \\
\hline$C D$ & 79 & M & GCS & 1 & $1 y$ & B cell lymphoma & \\
\hline UC & 57 & $M$ & GCS & 1 & 6 weeks & $\begin{array}{l}\text { Pneumocystis carinii. } \\
\text { Progressive pulmonary fibrosis } \\
\text { and respiratory failure }\end{array}$ & \\
\hline UC & 73 & M & GCS & 1 & 2 weeks & Post-op pulmonary embolism & \\
\hline UC & 67 & M & GCS & 1 & 2 weeks & $\begin{array}{l}\text { Postop septicaemia and } \\
\text { respiratory failure }\end{array}$ & \\
\hline$C D$ & 75 & M & Rectal GCS & $\begin{array}{l}3(0,2 \\
6 \text { weeks) }\end{array}$ & 6 weeks & $\begin{array}{l}\text { Purulent bronchitis with } \\
\text { recurrent septicaemia }\end{array}$ & \\
\hline
\end{tabular}

three patients (one with CD, two with UC) died from infectious complications (of which one occurred postoperatively), and pulmonary embolism led to death in one patient with UC following colectomy. Mean age was 62.7 years (range 25-70).

One further case of lymphoma developed in a patient with CD, a 24 year old woman with colonic CD in whom the indication for infliximab therapy was steroid refractory luminal disease in combination with a history of azathioprine intolerance. No other patient developed malignancy. The overall annual incidence of lymphoma was $1.5 \%$ in this cohort compared with an overall population based value of $0.015 \%$ in the background Swedish population

Two patients experienced severe opportunistic infections. One patient with UC had a fatal infection with Pneumocystis carinii, and one patient with CD was infected with Listeria meningitis but recovered. No cases of tuberculosis occurred in this cohort.

\section{Surgical intervention and 30 day postoperative outcome}

Forty one patients (mean age 39.5 (1.96) years (range 2077)) required major surgical treatment due to an unsatisfactory response to medical treatment. Thirty three of the operated patients had CD and eight had UC.

In 26 patients, colectomy was performed. Four had small bowel resections and in two patients the remaining rectum was removed post-colectomy. In one case a loop ileostomy was performed. One patient had a parastomal abscess that was drained. In the remaining seven patients surgical interventions were directed towards perianal fistulas.
Eleven cases (six CD and five UC) with severe complications were seen within the first 30 day postoperative period. Two of those complications were fatal, and both occurred in elderly men given infliximab off label for UC (one case of sepsis in a 67 year old man and one case of pulmonary embolism in a 73 year old man). Two further thromboembolic complications were seen following colectomy in patients with UC. Two cases of impaired wound healing were seen after proctectomy in patients with $\mathrm{CD}$ and in two cases colectomy was complicated by the development of pelvic abscesses (one CD and one UC) (table 3).

\section{Efficacy data}

The overall response rate in all forms of IBD was $75 \%$ $(\mathrm{n}=163)$. In $48 \%(\mathrm{n}=104)$ remission was achieved and in $25 \%$ infliximab failed to show any response $(n=54)$. No significant difference in response rates was seen between the different diagnostic groups.

\section{DISCUSSION}

The present study reports for the first time on the experience of infliximab in the clinical setting of IBD in a strictly population based cohort. The study comprised all IBD patients treated in Stockholm County between 1999 and 2001. This enabled us to assess infliximab therapy in an epidemiological context with regard to severe adverse events, including postoperative complications, serious infections, malignancies, and deaths. In our clinical experience with infliximab in an unselected IBD population, we encountered more severe adverse events than expected from earlier reports. ${ }^{18-20}$ A total of six deaths were seen; all of those

Table 3 Postoperative complications

\begin{tabular}{|c|c|c|c|c|c|c|c|}
\hline Diagnosis & $\begin{array}{l}\text { Age } \\
\text { (y) }\end{array}$ & Sex & $\begin{array}{l}\text { Concomitant } \\
\text { medication }\end{array}$ & $\begin{array}{l}\text { No of } \\
\text { infusions }\end{array}$ & Surgery & Complications & Specific comments \\
\hline$C D$ & 35 & $\mathrm{~F}$ & & 1 & Resection & $\begin{array}{l}\text { Anastomosis leakage and } \\
\text { septicaemia }\end{array}$ & \\
\hline$C D$ & 35 & $\mathrm{~F}$ & GCS + 5-ASA & 6 & Proctectomy & Impaired wound healing & \\
\hline$C D$ & 47 & $\mathrm{~F}$ & & 1 & Colectomy & Pelvic abscess & \\
\hline$C D$ & 36 & M & $\begin{array}{l}\text { Azathioprine }+ \\
\text { metronidazole }\end{array}$ & 6 & Fistula & Small bowel obstruction & \\
\hline$C D$ & 26 & M & $\begin{array}{l}\text { Azathioprine + GCS + } \\
\text { 5-ASA }\end{array}$ & 2 & Colectomy & Haematuria & \\
\hline$C D$ & 31 & $M$ & Azathioprine & 3 & Proctectomy & Impaired healing & \\
\hline UC & 38 & $\mathrm{~F}$ & Azathioprine +5 -ASA & 1 & Colon resection & Deep venous thrombosis & \\
\hline UC & 67 & M & GCS & 1 & Colectomy & Septicaemia & Fatal \\
\hline UC & 73 & M & GCS & 1 & Colectomy & Pulmonary embolism & Fatal \\
\hline UC & 20 & M & $\begin{array}{l}\text { Azathioprine + GCS + } \\
\text { metronidazole }\end{array}$ & 1 & Colectomy & Pelvic abscess & \\
\hline UC & 27 & $M$ & $\mathrm{GCS}+5-\mathrm{ASA}$ & 3 & Colectomy & Deep venous thrombosis & \\
\hline
\end{tabular}


patients had received a single dose $(5 \mathrm{mg} / \mathrm{kg})$ of infliximab. The annual mortality rate among IBD patients in Stockholm County has been historically low, with a standardised mortality ratio of 1.51 for CD and 1.37 for UC. ${ }^{21}$ Two of the fatalities occurred postoperatively, giving a mortality rate of $4.9 \%$, which is higher than that previously reported from St Mark's Hospital $^{22}$ in patients operated on for UC, and sixfold greater compared with contemporary material from Stockholm County comprising 381 patients with CD operated on between1985 and 1994 (Lapidus, personal communication).

A $2.8 \%$ mortality rate during a two year follow up of a Scandinavian cohort of IBD patients is exceptional and has not been reported previously. ${ }^{21}{ }^{23}$

Three patients developed lymphoma, two of which were fatal. In view of the young mean age of our study population, the number of lymphomas appears to be high. However, as our study population lacked a strictly matched control group (that is, with a similar disease pattern, duration, medication, etc), no definite conclusions can be drawn from the lymphoma cases that developed in the infliximab cohort. However, the annual overall incidence of non-Hodgkin-type lymphomas in Stockholm County was $0.015 \%$ in 2001 compared with the $>100$ times increased annual incidence of $1.5 \%$ in our cohort study. An age matched comparison results in a >1000-fold increase, as the occurrence of lymphomas in the 20-30 year old group of Swedish citizens is extremely rare.

However, controversy remains regarding the risk of lymphoma in IBD. Earlier reports from referral or hospital based IBD patients have demonstrated an increased baseline risk of lymphoma. ${ }^{24-28}$ Recent epidemiological studies from Sweden, Canada, and Italy are all suggestive of a low risk. ${ }^{12-15}$ Although patients in our study were recruited from a population based cohort, hospital or referral bias may have influenced the underlying risk of lymphoma. In one of the lymphoma patients, a 25 year old woman with CD, there was a very short time span between infliximab infusion and the diagnosis of malignant disease. Normally, this would suggest a lower probability of a causal relationship between malignancy and the study drug. However, we know little of the possible effects and temporal relations of infliximab in IBD patients prone to develop lympho- or myeloproliferative disease. Anti TNF- $\alpha$ blocking compounds may exert hitherto poorly understood effects that could facilitate the promotion of lymphoma development. This could imply that a short time frame between drug exposure and the diagnosis of lymphoma does not necessarily exclude a potential relationship. One of the other three lymphoma cases in this study was a 25 year old male who received one $5 \mathrm{mg} / \mathrm{kg}$ infusion and was diagnosed with a natural killer cell-type of lymphoma in the spleen one year later. This patient has previously been reported in the ACCENT l trial. ${ }^{4} \mathrm{He}$ succumbed six months after diagnosis despite having received several courses of anti-lymphoma cytotoxic drugs.

In patients with a high risk of infection, immunosuppressants should only be used after thorough consideration of the risk versus benefit ratio. Previous studies indicate that inhibition of TNF- $\alpha$ with infliximab may lead to specific rather than generalised immune suppression, ${ }^{29}{ }^{30}$ which theoretically would give infliximab a better risk-benefit profile compared with azathioprine/6-MP or cyclosporin. However, 101 cases of tuberculosis have been reported after infliximab therapy, and an association between this treatment and reactivation of tuberculosis has been deemed plausible. ${ }^{71}$ In the light of this, labelling of infliximab has been adjusted accordingly both in Europe and in the USA.

Considering the previously reported case of aspergillosis ${ }^{6}$ and our cases of fatal Pneumocystis carinii and life threatening
Listeria meningitis, it is reasonable to suspect that treatment with infliximab leads to an increased risk of potentially severe opportunistic infections. Whether or not infliximab treatment contributed to fatal septicaemia in the two elderly men in our study is difficult to ascertain as both men were at high risk of contracting infection. In the ACCENT 1 trial, two deaths from septicaemia were reported. One case was probably not associated with infliximab treatment but the other case, a 35 year old woman, died from sepsis following bowel resection after infliximab treatment. ${ }^{4}$

Overall, the variety of severe events associated with the use of infliximab for IBD in this study mirrors that reported recently from the Mayo Clinic. In that retrospective study, 500 patients received between one and 46 infusions and they reported three patients with malignancy, 41 patients with infectious events, and five deaths possibly related to infliximab. ${ }^{32}$

The efficacy of infliximab treatment in our study closely resembles the results of earlier controlled trials ${ }^{124}$ and those reported in other large open studies. ${ }^{18-20}$ We did not encounter significant efficacy differences between the IBD subgroups. Our off label experience in UC correlates well with previous small studies ${ }^{33}{ }^{34}$ but preliminary results from a randomised placebo controlled study of infliximab in GCS refractory UC were found to be negative. ${ }^{35}$

In conclusion, our study shows that the efficacy of infliximab, as demonstrated in controlled trials, is reproducible in a population based IBD cohort comprising mainly CD patients. However, a 3\% mortality rate in association with infliximab treatment implies that vigilance in drug surveillance needs to be emphasised, particularly with regard to opportunistic infections and development of lymphoma. In light of the observed severe adverse events, off label use of infliximab in UC cannot be recommended until prospective randomised trials have proven that the drug is appropriate for this indication.

\section{Authors' affiliations}

T Liung, P M Hellström, Department of Gastroenterology and Hepatology, Karolinska Hospital, Stockholm, Sweden

P Karlén, U Sjöqvist, Department of Medicine, Söder Hospital, Stockholm, Sweden

D Schmidt, Department of Medicine, St Göran Hospital, Stockholm, Sweden

A Lapidus, Department of Medicine, Ersta Hospital, Stockholm, Sweden I Janczewska, Department of Gastroenterology and Hepatology, Danderyds Hospital, Stockholm, Sweden

R Löfberg, IBD-unit, HMQ Sophia Hospital, the Karolinska Institute IBD Study Group, Stockholm, Sweden

\section{REFERENCES}

1 Targan S, Hanauer S, Deventer SV, et al. A short term study of chimeric monoclonal antibody CA2 to tumor necrosis factor alpha for Crohn's disease. N Engl J Med 1997;337:1029-35.

2 Present $D$, Rutgeerts $P$, Targan $S$, et al. Infliximab for the treatment of fistula in patients with Crohn's disease. N Engl J Med 1999:340:1938-405.

3 Rutgeerts P, Schreiber S, Columbel J, et al. Maintenance therapy with infliximab (Remicade ${ }^{T M}$ ) is safe, effective and steroid-sparing in Crohn's disease. Gut. 2001;49: abs No, 3051;(suppl III).

4 Hanquer S, Feagan B, Lichtenstein G, et al. Maintenance infliximab for Crohn's disease: the ACCENT I randomized trial. Lancet 2002;359:1541-9.

5 Kavanaugh A, Keenan G, Woody Kd, et al. Long-term follow-up of patients treated with infliximab (anti-TNF-aantibody) in clinical trials. San Fransisco: American Colleague of Rheumatology, 2001.

6 Warris A, Bjorneklett A, Gaustad P. Invasive pulmonary aspergillosis associated with infliximab therapy. N Engl J Med 2001;345:1098-104.

7 Keane J, Gershon S, Wise R, et al. Tuberculosis associated with infliximab, a tumor necrosis factor- $\alpha$ neutralizing agent. N Engl J Med 2001:345:1098-104.

8 Albina J, Mastrofrancesco B, Vessella J, et al. HIF-1 expression in healing wounds: HIF-lalpha induction in primary inflammatory cells by TNF-alpha. Am J Physiol Cell Physiol 2001;281:C1971-7.

9 Lee L, Efron D, Tantry U, et al. Inhibition of tumor necrosis factor-alpha attenuates wound breaking strength in rats. Wound Repair Regen 2000:547-53. 
10 Brown S, Green M, Gershon S, et al. Tumor necrosis factor antagonist therapy and lymphoma development: Twenty-six cases reported to the Food and Drug Administration. Arthritis Rheum 2002;46:3151-8.

11 Kornbluth A. Infliximab approved for use in Crohn's disease; a report on the FDA GI Advisory Committee conference. Inflamm Bowel Dis 1998:4:328-9.

12 Ekbom A, Helmick C, Zack M, et al. Extracolonic malignancies in inflammatory bowel disease. Cancer 1991;67:2015-19.

13 Persson P, Karlen P, Bernell O, et al. Crohn's disease and cancer; a population-based cohort study. Gastroenterology 1994;107:1675-9.

14 Loftus EJ, Tremaine W, Habermann T, et al. Risk of lymphoma in inflammatory bowel disease. Am J Gastroenterol 2000;9:2308-12.

15 Lewis J, Bilker W, Bressinger C, et al. Inflammatory bowel disease is not associated with an increased risk of lymphoma. Gastroenterology 2001;121:1080-7.

16 Connell W, Kamm M, Dickson M, et al. Long-term neoplastic risk after azathioprine treatment in inflammatory bowel disease. Lancet 1994;343:1249-52.

17 Fraser A, Orchard T, Robinson E, et al. Long-term risk of malignancy after treatment of inflammatory bowel disease with azathioprine. Aliment Pharmacol Ther 2002;16:1225-32

18 Cohen R, Tsang J, Hanaver S. Infliximab in Crohn's disease: First anniversary clinical experience. Am J Gastroenterol 2000;95:3469-77.

19 Ricart E, Panaccione R, Loftus E, et al. Infliximab for Crohn's disease in clinical practice at the Mayo clinic: The first 100 patients. Am J Gastroenterol 2001;95:722-9.

20 Farrell $R$, Shah $S$, Lodhavia $P$, et al. Clinical experience with infliximab therapy in 100 patients with Crohn's disease. Am J Gastroenterol 2000;95:3490-7

21 Persson $\mathrm{P}$, Bernell $\mathrm{O}$, Leijonmarck $C$, et al. Survival and cause-specific mortality in inflammatory bowel disease: a population-based cohort study. Gastroenterology 1996;110:1339-45.

22 Melville D, Ritchie J, Nicholls R, et al. Surgery for ulcerative colitis in the era of the pouch: the St Mark's Hospital experience. Gut 1994;35:1076-80S.
23 Jess T, Winther K, Munkholm P, et al. Mortality and causes of death in Crohn's disease: follow-up of a populatin-based cohort in Copenhagen County, Denmark. Gastroenterology 2002;122:1808-14.

24 Mir-Madjlessi S, Farmer R, Easley K, et al. Colorectal and extracolonic malignancy in ulcerative colitis. Cancer 1986;58:1569-74.

25 Greenstein A, Gennuso R, Sachar D, et al. Extraintestinal cancers in inflammatory bowel disease. Cancer 1985;56:2914-21.

26 Greenstein A, Mullin G, Strauchen J, et al. Lymphoma in inflammatory bowel disease. Cancer 1992;69:1119-23.

27 Farrell R, Ang Y, Kileen P, et al. Increased incidence of non-Hodgkin's lymphoma in inflammatory bowel disease patients on immunosuppressive therapy but overall risk is low. Gut 2000;47:514-19.

28 Arseneau K, Stukenborg G, Connors A, et al. The incidence of lymphoid and myeloid malignancies among hospitalized Crohn's disease patients. Inflamm Bowel Dis 2001;7:106-12.

29 Cope $A$, Londei $M$, Chu N, et al. Chronic exposure to tumor necrosis factor (TNF) in vitro impairs the activation of T cells through the T cell receptor/CD3 complex, reversal in vitro by anti-TNF antibodies in patients with rheumatoid arthritis. J Clin Invest 1994;94:749-60.

30 Meenan J, Hommes D, Dulleman HV, et al. The influence of TNF mAB cA2 on circulating lymphocyte population. Gastroenterology 1997;122:A1039.

31 Baker D, Clark J, Keenan G, et al. Tuberculosis occurring in patients receiving the anti-TNF- $\alpha$ agent infliximab. Arthiritis Rheum 2001;44(suppl):S105.

32 Colombel J, Loftus E, Tremaine W, et al. The safety profile of infliximab for Crohn's disease in clinical practice. The Mayo Clinic experience in 500 patients, Digestive Disease Week, 2003, Orlando, Florida..

33 Sands B, Tremaine W, Sandborn W, et al. Infliximab in the treatment of severe, steroid-refractory ulcerative colitis. Inflamm Bowel Dis 2001;7:89-93.

34 Chey W, Hussain A, Ryan C, et al. Infliximab for refractory ulcerative colitis. Am J Gastroenterol 2001;96:2373-81.

35 Probert CSJ, Hearing SD, Schreiber S, et al. Infliximab in moderately severe glucocorticoid resistant ulcerative colitis: a randomised controlled trial. Gut 2003;52:998-1002. 